\title{
Aggravated Colitis
}

National Cancer Institute

\section{Source}

National Cancer Institute. Aggravated Colitis. NCI Thesaurus. Code C35608.

Exacerbation of an underlying colitis. 